\title{
Fra laboratoriet til terapirommet
}

\author{
Av Bergljot Gjelsvik
}

\section{SAMMENDRAG}

Forskningsprogram som oversetter teorier til testbare hypoteser - translational research - har en sentral rolle i klinisk behandlingsforskning generelt, men er lite brukt som basis for utvikling av effektive og evidensbaserte behandlinger innen selvmordsfeltet. Cry of Pain-teorien og det teoretisk beslektede rammeverket Differential Activation for suicidalitet har vært toneangivende i prosessen med å nyansere myter om selvmordsatferd som et 'rop om hjelp', men like viktig er at den demonstrerer potensialet for translational research i selvmordsforskning. Artikkelen viser hvordan teorien har generert testbare hypoteser som i sin tur har lagt grunnlaget for nyskapende behandlinger. Den har derfor markert et veiskille i forskningstilnærmingen til behandlingsutvikling innen selvmordsfeltet.

Clark's (2004) translational research agenda in clinical psychological science has been extremely influential in treatments for anxiety and depression, but have been underutilised in suicide research. Williams's Cry of Pain theory of suicide highlights the potential for using this model in the context of treatment development in the suicide field. This paper outlines the theory, its evidence base and clinical implications. It is argued that research delineating mechanisms underpinning suicidal behaviour is key in the process towards more robust clinical treatments of people at risk of suicide and suicidal behaviour.
SOM FORBEREDELSE TIL et temanummer om forståelse og forebygging av selvmord spurte suicidologen Rory O'Connor nylig selvmordsforskere: Hva trenger vi i suicidologisk forskning i dag? Et av svarene fra vår forskningsgruppe var: Mer forskning som oversetter teorier og funn fra basalforskning til effektive kliniske intervensjoner (såkalt translational research). Innen klinisk psykologisk vitenskap har såkalte translational models of treatment development (Clark, 2004) fått et solid fotfeste. Innen selvmordsforskning og -forebygging, hvor effektive behandlingsmodeller er en vedvarende utfordring, har det inntil nylig vært relativt teorifattig når det gielder forhold som predikerer suicidale tanker, og forhold som bidrar til at et mindretall går fra å ha suicidale tanker til handling (Franklin et al., 2016). Dette er særlig viktig tatt i betraktning den relative mangelen på effektive behandlinger for suicidale pasienter.

Hensikten med denne artikkelen er å belyse potensialet for en «translational model of treatment development» for selvmordsforskning. Jeg vil belyse dette ved hielp av Cry of Pain-modellen (Williams, 1997; 2014). Denne modellen har hatt stor betydning for det kliniske selvmordsfeltet giennom sin kritikk og nyansering av myten om selvmordsatferd som «just a cry for help». «Suicidal behaviour», skriver Mark Williams (2014), «is never 'just' anything». 
Hvorfor er dette viktig? Vi vet fra systematiske litteraturstudier at helsepersonell ofte har en negativ innstilling til pasienter som blir lagt inn med suicidal atferd (Saunders et al., 2012), og at den bagatellisering som en slik terminologi representerer kan være belastende for sårbare individer. Den symbolske betydningen av denne modellen er derfor viktig. Hensikten med denne artikkelen er ikke primært å gå i detalj om modellen i seg selv, siden denne allerede er godt beskrevet i Williams sin bok, Cry of Pain: Understanding Suicide and the Suicidal Mind (1997; 2014). Jeg vil imidlertid her trekke frem en annen og kanskje mindre opplagt grunn til at denne modellen markerer en dreining i selvmordsfeltet: Modellen, dens beslektede Differential Activation Theory of Hopelessness/Suicidality (DAH) (Williams et al., 2008), og arbeidet dette rammeverket ga opphav til, markerte en endring i selve måten vi forsker på selvmord og suicidal atferd på. Valideringen av Cry of Pain og DAHrammeverket har gitt eksperimentelle metoder for å teste teorier om suicidalitet en plattform i selvmordsforskning, og har gitt eksperimentelt psykopatologidesign en relevans som man tidligere har sett mer av innen andre former for klinisk forskning.

\section{Hvorfor trenger vi teorier i selvmordsforskning?}

Av og til kan det være nyttig å se til tenkere innen psykologien mer generelt for vitaliserende innspill til selvrefleksion innen selvmordsfeltet. Psykologen og forskeren David Clark er en slik tenker. I en hyppig sitert artikkel (Clark, 2004) skisserer han en forskningsmessig og klinisk modell for å styrke utviklingen av evidensbaserte behandlingsmodeller som giør en forskjell. Clarks (2004) oppmoding om en klar strategi for behandlingsutvikling er særlig relevant i selvmordsfeltet hvor det til tross for lovende pilotstudier og enkeltstående randomiserte studier er en relativ mangel på evidensbaserte behandlinger og replikasjoner av behandlingsstudier, og hvor spørsmålet om klare strategier for effektiv behandlingsutvikling derfor er påtrengende.

Clarks (2004) modell utmerker seg ved sin vektlegging av teoriens rolle i god behandlingsutvikling, og har lagt grunnlaget for hans banebrytende forskning på angstlidelser. Clark (2004) argumenterer for at teoretiske modeller har betydning ved å være hypotesegenererende, i et format som kan testes empirisk. Han identifiserer følgende fem stadier i utviklingen av treffsikre behandlinger: (1) Et opplagt første skritt er å identifisere et avgrenset problem, det Clark kaller kjernepatologi. Deretter (2) å utvikle en teoretisk konsistent fortelling som forklarer hvorfor dette problemet vedvarer, inkludert hypoteser om hvilke mekanismer som opprettholder problemet. Det er her Cry of Pain-modellen, i denne sammenhengen, kommer inn. Slike modeller eller teorier kan deretter legge grunnlaget for (3) å teste 
antatte opprettholdende faktorer ved hielp av stringente eksperimenter. På basis av slike empirisk validerte opprettholdende faktorer vil et neste skritt deretter være (4) å utvikle behandlinger som har til hensikt å reversere eller modifisere disse opprettholdende faktorene, og (5) å teste effekten av disse i randomiserte kontrollerte studier. Prosessen stopper selvsagt ikke her - hvis studiene ikke gir de resultatene man forventer, gir dette grunnlag for nye og reviderte «kart» av hva som opprettholder problemet. La oss nå se på relevansen av dette for selvmordsfeltet, med utgangspunkt i Cry of Pain og beslektede rammeverk.

\section{Teoretiske rammeverk: Cry of Pain og Differential Activation Hypothesis (DAH)}

Cry of Pain-modellen tok delvis utgangspunkt i observasjoner av hvordan dyr reagerte når de ble utkonkurrert av andre i stammen, inspirert av Gilbert (1989). Fugler som taper slåsskamp mot andre fugler i åpent landskap, skriver Williams og kolleger (2015), flyr simpelthen videre, og klarer seg bra. Dersom kampen derimot skjer i et avgrenset område, som et bur, hvor de ikke kan flykte, fremtrer reaksjoner i «taperen» som vi i dag kjenner igien som typiske fra dyp depresjon, inkludert lutet kroppsholdning, nedtrykt, «with drooping wings and head in the dust» (Williams et al., 2015, s. 18) i fravær av noen form for fysisk skade. I Cry of Pain-modellen bruker Williams slike observasjoner for å danne hypoteser om hvordan dette utfolder seg for mennesker i suicidale kriser. Modellen postulerer at det ikke bare er denne opplevelsen av å være utkonkurrert/ utmanøvrert som er tilstrekkelig for at noen skal bli suicidal, de må også oppleve at de er fanget (entrapped) og at det ikke er noen vei ut (no rescue), det evolusjonspsykologen Paul Gilbert (1989) kaller arrested flight. Opplevde eller internaliserte symboler på at man føler seg som en taper eller som fanget, sier modellen, kan sammenlagt trigge en suicidal krise.

Mens det finnes mange og gode modeller for «distal» sårbarhet over tid, er Cry of Pain en modell som forklarer det vi kan kalle krisereaktivitet - den går ikke inn på distale risikofaktorer, men heller hva som kan forklare at dramatiske suicidale kriser kan komme brått og uventet. I klinisk kontekst ønsker vi imidlertid ikke bare å avklare hva som giør at suicidale tanker og impulser blir aktivert, men betingelsene for at de er tilbakevendende. Differensiell aktiveringsteori (DAH; Williams et al., 2008, Williams et al., 2016) postulerer at lavt stemningsleie ved depresion, og fungerer som en kontekst

\section{Mens det finnes mange og gode modeller for «distal» sårbarhet over tid, er Cry of Pain en modell som forklarer det vi kan kalle krisereaktivitet.}

for koaktivering av negativt tankeinnhold («ingen vil noengang elske meg») og maladaptive prosesseringsmodi (e.g. tunnelsyn, grubling, unnvikelse) - som til sammen skaper en depressiv respons, eller «mindlock» (Gjelsvik, 2014). I følge dette rammeverket kan sårbarhet for tilbakevendende suicidalitet forklares med individuelle forskjeller i hvor lett denne depressive modusen blir reaktivert ved temporært lavt stemningsleie (Williams et al., 2008).

Med dette har vi altså et teoretisk rammeverk som gir hypoteser om hva som både skaper suicidal grobunn, og hva som giør at dette vedvarer. Modellen predikerer at lavt stemningsleie avdekker sårbarhetsfaktorer som vi kjenner fra Cry of Pain-modellen (e.g., intrusive selvmordstanker og bilder knyttet til å være ekskludert, lav problemløsning, følelse av å være fanget) som ikke vil være synlige ved normalt stemningsleie. DAH-modellen predikerer at mens folk flest fort rister av seg midlertidig sårbarhet, vil det for individer med en historikk med suicidal sårbarhet kunne utløse et sett med både negativt tankeinnhold og maladaptive kognitive bias som fyrer opp under, fasiliteter og opprettholder suicidale kriser. Hvilken evidens er det for dette?

\section{Eksperimentell psykopatologi i selvmords- forebyggingens tjeneste}

For å teste disse prediksjonene har forskere blant annet brukt såkalt mood induction-design, som innebærer å kunstig indusere lavt stemningsleie i laboratoriet. Fordelen med slike design er at man kan ha streng eksperimentell kontroll over faktorer som spiller inn, og måle hvorvidt faktorer man er interessert i, som for eksempel følelse av å være fanget (entrapped), kommer til syne når stemningsleiet er (kunstig) nedstemt på tvers av ulike kliniske grupper. Dette kan giøres ved ulike metoder - i laben til Mark Williams brukte de typisk depressiv musikk og negative, selv-refererende utsagn («I'm no good»). Hvis vi eksponeres for depressivt innhold vil de fleste føle seg midlertidig nedstemt. Det er betydelig evidens for at disse prediksjonene stemmer. Når personer med en historikk med tilbakevendende suicidal depresjon, men som nå er friske, blir giort kunstig triste, kommer lav problemløsningsevne (Williams et al., 2005), overgenerell hukommelse (Williams et al., 2007) og svekket evne til å generere fremtidige hendelser (future fluency, Williams, Van der Does, Barnhofer, Crane, \& Segal, 2008) til syne. Det betyr at lavt stemningsleie avdekker latent sårbarhet som ikke var synlig før det lave stemningsleiet ble indusert. Dette genererer håpløshetsfølelse, som i sin tur kan skape en følelse av å være fanget: Fortiden er vag, fremtiden er vag, og her og nå er fylt med håpløshetsfølelse. En styrke med å validere disse forholdene eksperimentelt er at man med stor sikkerhet kan etablere at det er en kausalsammenheng mellom en faktor (lavt stemningsleie) og dens effekt (kognitive bias, for eksempel lav problemløsningsevne). Et viktig spørsmål er imidlertid 


\section{Et viktig budskap fra denne rekken av studier er at effekten av tidlige traumer på selvmordsfare her og nå kan virke giennom å påvirke problemløsningsevne.}

hvilken relevans funn i et laboratorium har for hvordan disse fenomenene utspiller seg i hverdagen. En måte å undersøke dette på er ved å bruke andre og komplementære metoder, som longitudinelle studier. Lav problemløsningsevne, som i studien til Williams og kolleger (2006), og den assosierte følelsen av å være fanget (entrapment), er funnet å predikere reinnleggelse med suicidal atferd (O'Connor et al., 2014; 2017). Dette er et eksempel på hvordan Clarks mal for forskning kan komme til live og ha relevans i selvmordsforskningssammenheng: Teorier (Cry of Pain) kan testes, og vi kan dermed eksperimentelt «fange» faktorer som man faktisk kan jobbe med, og modifisere, i klinisk kontekst. Et viktig budskap fra denne rekken av studier er at effekten av tidlige traumer på selvmordsfare her og nå kan virke giennom å påvirke problemløsningsevne. Slik kan vi gradvis identifisere individuelt sensitive markører for risiko, som både kan testes eksperimentelt, og ha klinisk impact.

Med Clarks (2004) fjerde og femte trinn (utvikle behandlinger og giennomføre RCT-er) kan vi spørгe, hva er de kliniske implikasjonene av denne forskningen? Hvis dette er del av de komplekse prosessene som driver suicidal tenkning, hva kan denne gruppen trenge? Kliniske innsikter fra dette arbeidet peker i retning av behov for okt metakognitiv bevissthet, det vil si, en evne til å betrakte tanker som tanker, snarere enn å bli fanget inn av tankenes mening og implikasjoner for selvet. Williams og kolleger (2015) summerer opp dette pilotarbeidet i boken Mindfulness and the transformation of despair - en viktig bok, ikke bare for dens utlegning av det viktige arbeidet med suicidale pasienter, men like mye for beskrivelsen av veien dit, via eksperimentell psykopatologi.

Hva er den videre betydningen av eksperimentell psykopatologi for selvmordsfeltet? Hensikten med Clarks (2004) modell var å legge en god basis for effektiv behandlingsutvikling innen klinisk psykologi. I et felt hvor vi trenger effektive behandlinger kan dette være av interesse. Jeg har her argumentert for at Cry of Pain-modellen og den effekt denne har hatt på selvmordsforskningen illustrerer potensialet for teorier som utgangspunkt for hypotesedannelse og for deretter å kunne teste disse i eksperimentelle studier. Godt funderte risikomekanismer kan i sin tur informere utviklingen av treffsikre behandlinger. Vi viderefører nå forskningen på mekanismer som ligger til grunn for vedvarende sårbarhet. I The Mindlock Project undersøker vi hvordan intrusive bilder påvirker suicidal sårbar- het, og hvordan ulike prosesseringsmodi predikerer suicidalitet, ved hielp av eksperimentelle, kvalitative metoder og neuroimaging. Hensikten er å bygge opp mer presis kunnskap om modifiserbare sårbarhetsfaktorer og, i tråd med Clarks (2004) resonnement, å utvikle mer presise modeller for behandling. En viktig ledetråd i dette arbeidet, inspirert av Cry of Pain-modellen og forskningen den har avlet, er at eksperimentell forskning som kan lede til identifisering av matnyttige risikofaktorer, har en sentral plass som fundament for utvikling av behandlinger som i sin tur kan testes ved randomiserte kontrollerte studier. Eksperimentell forskning som innfallsvinkel kan derfor komplementere eksisterende forskningstilnærminger.

\section{Mind the gap: Overgangen fra tanke til handling}

Modeller for forståelse av suicidalitet og selvskading er sentrale kart for å navigere i et vanskelig terreng. Cry of Pain er primært en modell som forklarer og genererer hypoteser om omstendighetene som giør at noen blir suicidale. Teorier om selvmordsatferd har, som påpekt innledningsvis, en sentral funksjon som kart til å navigere det komplekse terrenget som selvmordsatferd er, og sette premisser for forskning. En svakhet ved Cry of Pain-modellen er at den ikke forklarer det som i dag er den store gåten i selvmordsforskning og -forebygging: Prosessene som bringer et bekymringsfullt mindretall fra tanke til handling. Dette er det behov for å forstå bedre. Bruker vi Clarks (2004) modell som basis for kunnskapsutvikling, blir det klart at vi trenger teorier som også tar dette i betraktning. Det er gode holdepunkter for å anta at risikofaktorene for selvmordstanker er forskjellige fra risikofaktorene som predikerer overgang til handling (Nock, Kessler, \& Franklin, 2016). De ulike fasene av den suicidale prosessen kaller på ulike forklaringer, som O'Connors (2011; 2016) modell illustrerer. Cry of Pain var en viktig inspirasjon for deler av O'Connors (2011) modell, Integrated MotivationalVolitional Model of Suicidal Behaviour, som sammen med en ny generasjon teoretiske nyvinninger giennom det siste tiåret adresserer dette kunnskapshullet (e.g.; Ioiner, 2005; May \& Klonsky, Burke \& Alloy, 2016; Valach, Michel, \& Young (2016, in Michel, Valach, \& Gysin-Maillart, 2017). Det er allerede lovende eksempler på at prediksjonene fra noen av disse modellene blir testet systematisk (se for eksempel Dhingra et al., 2016). Det er å håpe at denne typen forskning, i tråd med Clarks (2004) agenda, på sikt vil føre til presise og robuste behandlingsmodeller.

\section{REFERANSELISTE}

Burke, T. A., \& Alloy, L. B. (2016). Moving Toward an Ideation-to-Action Framework in Suicide Research: A Commentary on May and Klonsky. Clinical Psychology: Science and Practice, 23, 26-30. doi:10.1111/cpsp.12134

Clark, D. M. (2004). Developing new treatments: On the interplay between theories, experimental science and clinical innovation. Behaviour Research and Therapy, 42, 1089-1104. doi:10.1016/i.brat.2004.05.002 


\section{Du er her}

Dhingra, K., Boduszek, D., \& O'Connor, R. C. (2016). A structural test of the integrated motivational-volitional model of suicidal behaviour. Psychiatry Research, 239, 169-178.

Franklin, I., Ribeiro, I. D., Bentley, K. H., Huang, X., Musacchio, K. M., Chang, B. P., (...) \& Nock, M. K. (2016). Risk Factors for Suicidal Thoughts and Behav iors: A Meta-Analysis of 50 Years of Research. Psychological Bulletin, 143, 187-232.

Gilbert, P. (1989). Human nature and suffering. Lawrence Erlbaum Associates: Hove.

Joiner, T.E. (2005). Why people die by suicide. Cambridge, MA: Harvard University Press.

May, A. M., \& Klonsky, E. D. (2016). What distinguishes suicide attempters from suicide ideators? A meta-analysis of potential factors. Clinical Psychology: Science and Practice, 23, 5-20. doi:10.1111/cpsp.12136

Nock, M. K., Kessler, R. C., Franklin, I. C. (2016). Risk factors for suicide ideation differ from those for the transition to suicide attempt: The importance of creativity, rigor, and urgency in suicide research. Clinical Psychology: Science and Practice, 23, 31-34

O'Connor, R. (2011). The integrated motivational-volitional model of suicidal behaviour. Crisis, 32, 295-298 doi: 10.1027/0227-5910/9000120.

O'Connor, R.C., \& Portzky, G. (in press). The relationship between entrapment and suicidal behavior through the lens of the integrated motivation al-volitional model of suicidal behavior. Current Opinion in Psychology, 22, 12-17.

Saunders, K., Hawton, K., Fortune, S., \& Farrell, S. (2012). Attitudes and knowledge of clinical staff regarding people who self-harm: a systematic review. Journal of Affective Disorders, 139, 205-216. doi: 10.1016/i. jad.2011.08.024.

Williams, I. M. G., Barnhofer, T., Crane, C., \& Beck, A. T. (2005). Problem solving deteriorates following mood challenge in formerly depressed patients with a history of suicidal ideation. Journal of Abnormal Psychology, 114, 421-431.

Williams, J. M. G., Van der Does, A. I. W., Barnhofer, T., Crane, C., \& Segal, Z. S. (2008). Cognitive Reactivity, Suicidal Ideation and Future Fluency: Pre liminary Investigation of a Differential Activation Theory of Hopelessness/ Suicidality. Cognitive Therapy and Research, 1, 83-104.

Williams, I. M. G. (2014). Cry of pain. Understanding suicide and the suicidal mind. 3. utgave. London: Piatkus.

Williams, I. M. G., Fennell, M., Barnhofer, T., Crane, B., \& Silverton, S. (2015). Mindfulness and the transformation of despair. Working with people at risk of suicide. New York: Guilford Press.

Williams, I. M. G., Duggan, D., Crane, C., Hepburn, S., Hargus, E., and Gjelsvik, B. (2016). Modes of mind and suicidal processes. I R. O'Connor \& I. Pirkis, International Handbook of Suicide Prevention. New York: Wiley Blackwell.

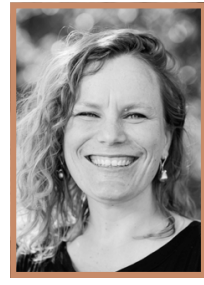

Foto: Tommy Ellingsen
BERGLJOT GJELSVIK er psykolog og selvmordsforsker basert ved Universitetet i Oslo og Centre for Suicide Research, University of Oxford. Gjelsvik leder the Mindlock Project (www.mindlockproject.org) med fokus på mekanismer til grunn for tilbakevendende suicidalitet, og jobber klinisk med deprimerte og suicidale pasienter.

\section{Jeg husker deg ikke så godt \\ lenger \\ Men jeg kjenner ditt smil}

Din latter

Din fortvilelse

Ditt nærvær

så sterkt

Ditt evige fravær

skjærer i hjertet

Som et spyd

Som et spyd

Du er borte for all tid

Og allikevel er du her

Dypt i hjertet for all tid

Og snart skal vi onske hverandre

\section{Godt Nytt År}

\section{Jon Schultz}

